\title{
RELACIONES DE «SOLIDARIDAD»EN EL ADVERBIO EN -MENTE
}

\author{
Mario García-PAGE \\ UNED (Madrid)
}

\begin{abstract}
RESUMEN
The phenomenon of lexical solidarity does not appear to be exclusive to the verbal predicates and adjetives chosen by SSNN, as similar lexical/semantic relationships occur between some adverbs ending in -mente and the verbs or adjectives they modify (prohibir/prohibido: terminantemente, cerrar/cerrado: hermeticamente, loco: perdidamente, llover: torrencialmente, etc.
\end{abstract}

1. Siguiendo las observaciones de Porzig (1934), Eugenio Coseriu (1967), en un estudio harto conocido en el ámbito de la semántica estructural, determinó tres tipos de relaciones sintagmáticas que pueden contraer ciertas unidades léxicas del sistema de la lengua, según que sea el clasema (afinidad), el archilexema (selección) o el propio lexema (implicación) el elemento determinante que funciona como rasgo distintivo en el significado de otra unidad léxica (o lexema determinado $)^{1}$. Estos tipos de relaciones semánticas «orientadas» se conocen bajo el término genérico, acuñado definitivamente por Coseriu $(1967,1968$ : 182-4), de solidaridades léxicas.

La interesante teoría del lingüista rumano, no obstante vaga en algunos puntos y parca en ilustraciones, se divulgó con rapidez y ha sido generalmente aceptada sin modificaciones.

1 «Una solidaridad léxica puede ahora definirse como determinación semántica de una palabra por medio de una clase, un archilexema o un lexema, precisamente, en el sentido de que una clase determinada, un determinado archilexema o un determinado lexema funciona como rasgo distintivo de la palabra considerada. Dicho de otro modo, se trata del hecho de que una clase, un archilexema o un lexema pertenece a la definición semántica de esa palabra, en el plano de las diferencias semánticas mínimas (rasgos distintivos). Por lo tanto, no se trata de una relación entre sólo dos palabras; ello, ni siquiera en el caso de una determinación por medio de un lexema» (Coseriu 1967:148-9). 
Dentro de la lingüística española, es tal vez Gutiérrez Ordóñez (1989:114-6) uno de los pocos estudiosos que, en un brevísimo apunte de apenas dos páginas, hace una revisión del tema. Según el citado autor, los tres tipos de solidaridades delimitadas por Coseriu se reducen a un solo grupo: la afinidad, ya que «todas las solidaridades son fenómenos clasemáticos» en la medida en que «los lexemas determinantes se corresponden siempre con clasemas». Además, «las solidaridades no son, pues - añade Gutiérrez-, 'fenómenos sintagmáticos condicionados paradigmáticamente', sino fenómenos paradigmáticos condicionados sintagmáticamente» (Gutiérrez 1989:116).

Los manuales que tratan, normalmente de forma somera, las solidaridades léxicas no suelen apartarse, en lo fundamental, de la teoría de Coseriu, e, incluso, utilizan sus mismos ejemplos, basados en la combinatoria de algunas de estas tres categorías: el sustantivo, el verbo y el adjetivo (caballo: alazán, perro: ladrar, etc.).

Más que en el plano teórico es en este aspecto de las ilustraciones en el que debe mencionarse un trabajo (Bosque 1982) que, aunque consagrado a trazar las líneas generales de una posible gramática de los fenómenos de lexicalización, trata de plano las solidaridades léxicas como un subgrupo del código semántico del lenguaje literal. $Y$, en efecto, la solidaridad, aun siendo producto de la técnica libre del discurso, tiene muchas concomitancias con los fenómenos de fijación lingüística, incluso pragmática. En dicho trabajo, su autor hace una clasificación por categorías - no exhaustiva- de los lexemas que, bien por su sentido «recto», bien por su sentido «figurado», pueden formar una solidaridad en virtud de las restricciones de selección que se les impone semántica y pragmáticamente. Tal clasificación representa en sí misma una amplia ilustración del fenómeno por cuantos variados ejemplos se aducen.

$\mathrm{Y}$ así, junto a la existencia de predicados verbales que restringen las posibilidades de elección de SSNN en función de objeto o sujeto y de predicados adjetivos que restringen las posibilidades de selección de núcleos nominales ${ }^{2}$, Bos-

2 A continuación, se expone una relación de unidades léxicas no adverviales que se asocian solidariamente en español (algunos ejemplos del corpus están extraídos de Bosque 1982):

verbo: selección de SN (CD)

repicar: campanas

trinchar: carne, pescado

guiñar: ojo

bruñir: metal

labrar: tierra (sent. «recto»), futuro, porvenir

(sent. fig.)

esgrimir: armas (sent. «recto»), argumentos

(sent. fig.)

frugal: comida

encarnizado: batalla, lucha

botionda: cabra

verrionda: cerda

torionda: oveja

zafarí: higo/granada/naranja

adjetivo: selección de núcleo nominal

verbo: selección de SN (Suj.)

avecinarse: tormenta, temporal, período de tiempo marcado negativamente, problema, dificultad, suceso negativo arreciar: lluvia, temporal, vendaval, frío ímprobo: esfuerzo, trabajo, labor mazarí: loseta, baldosa bizantino: relativo a Bizancio (sent. «recto»), discusión (sent. fig.) redondo: objetos (sent. «recto») trabajo, negocio, asunto (sent. fig.). 
que (1982:141) señala tres casos de solidaridad en los que una unidad léxica adverbial selecciona un verbo o un adjetivo: torrencialmente: llover, ?nevar; diametralmente: opuesto; terminantemente: prohibir. Se trata de tres adverbios en -mente que, por su posible sentido traslaticio, seleccionan esa clase de predicados. Si bien es verdad, ya anteriormente Beinhauer (1930:282-3, 328-9) había apuntado certeramente la muy estrecha relación que mantienen ciertos adverbios con adjetivos participiales (diametralmente: opuesto, herméticamente:cerrado), así como el adjetivo torrencial respecto del sustantivo lluvia. También E.R. Egea (1979:cap. 3), en su extenso estudio sobre el adverbio en -mente, ya indica - aun sin utilizar el término «solidaridad»- el alto grado de condicionamiento sintagmático que se produce entre ciertos predicados verbales y un gran número de adverbios de manera en -mente.

En un estudio nuestro (García-Page 1993), sugeríamos la complementación de esa pequeña nómina de adverbios en -mente que pueden contraer una relación de solidaridad con otras piezas léxicas, proponiendo unidades adverbiales como opiparamente (:comer, con 'abundancia'), frugalmente (:comer, con 'escasez'), herméticamente (:cerrar, cerrado), o rematadamente (:loco, ?enfermo).

Igualmente, siguiendo el propósito de ampliar el paradigma de unidades que pueden establecer una relación de solidaridad, indicábamos en otro trabajo anterior (García-Page 1990a) la posibilidad de encontrar algún tipo de «implicación», semejante al que se produce entre los términos conformantes de un fenómeno de solidaridad, entre ciertas locuciones y las categorias a que modifican (de reojo: mirar, ?ver; como una tapia: sordo; etc.), o, preferentemente, entre los miembros configuradores de la propia locución (regañadientes: a; vilo: en, etc.), especialmente cuando ésta se compone de un binomio, reversible o irreversible, del tipo moxte: ni oxte ni _ (Malkiel 1959; Morawski 1927, 1929) o incluye una «palabra idiomática», como en los ejemplos antes citados y en otros como santiamén: en un _(García-Page 1990b, 1991). Esta observación también podría aplicarse, mutatis mutandis, a un gran número de refranes bimembres ( $c f r$., en relación con el fenómeno de aposiopesis, García-Page 1990c, 1990d).

2. En efecto, la categoría adverbio también parece disponer de la facultad de seleccionar otra clase de palabra con la que entabla una relación de solidaridad léxica. $Y$, aunque esta facultad no se extienda a todas las formas adverbiales, sino más bien sólo a unas pocas (generalmente, acabadas en -mente), lo cierto es que el adverbio funciona en tales casos de forma idéntica a las dos fundamentales categorías predicativas, el verbo y el adjetivo; las únicas que, a saber por los estudios tradicionales al respecto, podrían restringir sus posibilidades de elección de otros signos.

Si nos fijamos en la siguiente nómina de adverbios en -mente:

diametralmente rotundamente rematadamente tangencialmente herméticamente literalmente 
frontalmente materialmente textualmente

torrencialmente mortalmente vertiginosamente

encarnizadamente remotamente denodadamente

terminantemente perennemente afanosamente

tajantemente apoteósicamente prolijamente

categóricamente perdidamente celosamente

radicalmente locamente elocuentemente

puede afirmarse, con tal vez un no amplio margen de error, que tales signos establecen, en su empleo normal (habitual), relaciones de solidaridad con otras piezas léxicas, preferentemente verbos. No es, evidentemente, una situación imposible el que alguno de estos adverbios pueda formar parte de otra estructura no dominada por un caso de solidaridad, es decir, que no esté funcionando solidariamente; situación que se produce de modo especial en estructuras en las que interviene, más que otra razón, la actividad creativa del usuario, aun cuando no se intente conscientemente contravenir las reglas del código lingüístico estándar. Ya Coseriu (1967:159) indicaba esta posibilidad al afirmar que «la solidaridad no implica que los lexemas determinados solidariamente no puedan en absoluto emplearse con lexemas que no participan de la solidaridad correspondiente: pueden emplearse con tales lexemas, pero, en este caso, se hace patente, precisamente, la no solidaridad de los términos sintagmáticamente enlazados, con lo cual el empleo se vuelve un empleo 'metafórico'».

Como puede inferirse de lo hasta ahora expuesto, preferimos hablar con cierta generalización o vaguedad de solidaridad, aun cuando resultara interesante precisar, en caso de ser posible, qué tipo de solidaridad (implicación, selección o afinidad) se establece en cada uno de los casos. Abundan las relaciones de implicación, incluso de doble o múltiple implicación, pero también existen casos de selección y de afinidad, independientemente de que los ejemplos pudieran describirse, de seguir la propuesta de Gutiérrez Ordóñez (1989), como fenómenos clasemáticos. Por ejemplo, textualmente no presenta una relación de monogamia linguística, típica de la implicación, ya que no se combina exclusivamente con un único signo, sino que se suele emplear con ciertos verbos que expresan la acción de reproducir un texto: citar, copiar, repetir, reproducir, etc.; y, por extensión, cuando el contexto lo permita, con verbos de mayor generalidad que aquéllos, a los que incluyen, como leer o decir; v.gr.: «E1 Presidente del Gobierno Español dijo textualmente...» (rueda de prensa ofrecida por televisión).

En otro orden de cosas, cabe señalar que ciertos adverbios en -mente preservan la relación de solidaridad léxica que los adjetivos originarios de que derivan establecen con otras unidades léxicas (sustantivos), tal como sucede con frugal (:comida[escasa]); opiparo (:comida[abundante]); frontal (:choque, oposición, golpe); hermético (:cierre), etc.; v.gr.: 
ADJETIVO: restricc. de $\mathrm{N}$

opíparo: comida, *aperitivo, *tentempié, *banquete

frugal: comida, *comilona,

*banquete, ${ }^{*}$ tentempié

frontal: choque, golpe,

oposición oponerse

hermético: cierre
ADVERBIO: restricc. de V

opíparamente: comer

frugalmente: comer

frontalmente: chocar, golpear,

herméticamente: cerrar

Evidentemente, la conservación de la solidaridad no es la única semejanza que pueda determinarse entre el adjetivo y el adverbio. Por ejemplo, ciertos adverbios en -mente tienen la particularidad de preservar el tipo de rección preposicional que imponen los adjetivos de que derivan (Gunnarson 1986, Bosque 1989:135, Garcia-Page 1993), especialmente aquéllos que indican relaciones temporales o espaciales: perpendicular/perpendicularmente a, proporcional proporcionalmente a, paralelo/paralelamente a, etc.

A hechos como éste habría que sumar la existencia en español de ciertos predicados verbales que, en condiciones normales, exigen una complementación necesariamente «circunstancial» o, como sugieren Hernanz-Brucart (1987:271-3), «pseudo-circunstancial» (adv o SP) para configurar una estructura oracional gramaticalmente bien formada, tal como es el caso de portarse o comportarse, que requieren la copresencia de adverbios modales o gradativos axiológicos (mal, bien, regular, perfectamente, etc.) o bien de estructuras con valor circunstancial (como era de esperar, de maravilla, etc.). En cuanto que la aparición de este tipo de complementaciones depende exclusivamente de las exigencias léxicas del verbo (se trata de elementos subcategorizados y no libres, elementos conformadores de la estructura argumental del predicado), el verdadero problema que subyace a estas estructuras (comp. Juan se portó correctamente/* Juan se portó) es qué función sintáctica debe asignarse al complemento (CC o CRég) ${ }^{3}$; problema, no obstante, que plantean no pocos verbos de otra naturaleza que requieren complementos locativos y temporales (encaminarse, dirigirse, empezar, ir,...) o de otra índole (p.e., vestir: Marta viste ropa caral a la modal de rojol elegantementel elegante - *Marta viste).

3 Sobre este particular y otros aspectos relativos al suplemento, véanse, entre otros: Alarcos (1969), (1986), (1990a); Bosque (1983a); Rojo (1985) y (1990); Martínez (1986) y (1987-88); Gutiérrez (1986) y (1987); Porto (1987a), (1987b), (1992:38-44) y (1993:12-3); Álvarez (1987); Millán (1988); Pérez (1989); Hernández (1990); Femández (1991); González (1991); Vera (1992).

Interesantes observaciones sobre este aspecto y cuestiones conexas pueden verse además en Vallejo (1925); Niculescu (1959); Tesnière (1959); Blinkenberg (1960); Alarcos (1968); López (1970); Boons (1976); David (1976); Rebolo (19760-77); Haap (1977) y (1978); Chervel (1979); Molho (1980); Cano (1981) y (1983); Bosque (1983b); Leeman (1985-86); Díez (1987-88); Náñez (1988). 
La posibilidad de que el adverbio en -mente contraiga una relación de solidaridad con un verbo o adjetivo se debe en ocasiones a que el adverbio ha adquirido un sentido figurado que no le es propio al adjetivo de que deriva. Así, parece que adverbios como materialmente, perdidamente o rematadamente se desvían, en al menos algunos de sus usos, del significado originario de material, perdido y rematado, respectivamente; circunstancia que no se observa en otros, como herméticamente: hermético, frontalmente: frontal, etc.

Es más, hay algunos adverbios que proceden de adjetivos fácilmente refractarios a la sufijación adverbial, tal como ocurre con los participios de presente (terminantemente: terminante).

Aun existiendo ciertas restricciones morfológicas y semántico-pragmáticas para la formación de adverbios en -mente, es recurso frecuente la creación de unidades léxicas sufijadas con -mente que contravienen las normas, de modo especial en la lengua literaria, el habla coloquial o el lenguaje de la publicidad. Al margen de formaciones adverbiales anómalas, en extremo extravagantes, del tipo verdemente (adjetivo), tuyamente (pronombre) o corazónmente (sustantivo), entre otros casos (Mayoral 1982, García-Page 1991), se debe a la creatividad del hablante la existencia de construcciones como «comer pantagruélicamente», «discutir bizantinamente un asunto» 0 «el árbol crece frondosamente», cuando sí son legítimas «comida pantagruélica», «discusión bizantina» o «árbol frondoso». Cabe reparar, incluso, en que, en el código figurado del adjetivo bizantino, existe una auténtica relación de solidaridad léxica (discusión: bizantina).

3. Aunque todos los adverbios arriba indicados (\$2) establecen o pueden establecer una relación de solidaridad con otro signo, lo cierto es que no todos presentan los mismos comportamientos ante ciertas pruebas. A continuación se expone un breve análisis de cada uno de ellos.

1) diametralmente

$\mathrm{E}$ l adverbio diametralmente sólo se usa formando grupo solidario con los predicados oponer (V) u opuesto (A), en sus diferentes formas flexivas, y, por el significado que adquiere en tales contextos, se aproxima a totalmente, completamente. Su empleo no es posible con sinónimos de opuesto, como contrario, enemigo, opósito, etc.; comp. diametralmente (totalmente): opuesto / *diametralmente (totalmente): contrario.

La forma diametral, adjetivo de que deriva, no se combina con signos como oposición, enemigo, opósito, etc.; comp. *diametral: oposición/total: oposición.

\section{2) tangencialmente}

El uso de tangencialmente queda prácticamente confinado a verbos de lengua como hablar (de un asunto), referirse, tratar, mencionar, ?aludir, cuando se trata un asunto o tema; contextos en los que adquiere el sentido de 'indirectamente' o 'superficialmente', y, por lo tanto, puede combinarse, formando oposi- 
ción, con el adverbio directamente: «El Ministro de Transportes tratará, directa o tangencialmente, el tema de la subida del precio de los carburantes».

Por el significado 'de forma indirecta' atribuible a tangencialmente, éste puede guardar cierta relación con el modismo irse/salirse por la tangente, fig. y fam. 'valerse de un subterfugio o evasiva para salir de un apuro', pero no con el adjetivo tangencial (no registrado en el DRAE), cuyos contextos de uso no comparte con aquél, a excepción de los casos en que tangencial forma parte del SP de modo tangencial (= tangencialmente) u otros semejantes.

\section{3) frontalmente}

Aunque el DRAE no documenta la forma frontalmente, su empleo es frecuente en estructuras sintagmáticas cuyo núcleo predicativo es el verbo oponerse o chocar, y, en menor medida, otros de significado parecido, como golpear (??golpearse). También se emplea con los participios de dichos verbos: opuesto frontalmente.

La solidaridad del adverbio con tales signos es semejante a la relación mantenida entre el adjetivo originario, frontal, y los nombres deverbales choque y golpe, y oposición.

\section{4) torrencialmente}

Tampoco el DRAE registra el adverbio torrencialmente, pero su uso está permitido. Aparece de forma muy restringida en combinaciones del mismo con el verbo llover (y, si acaso ?nevar), aun en el supuesto de que llover se emplee en sentido figurado: «Por la pésima actuación del árbitro, empezaron a llover botes, almohadillas, piedras, hasta ocultar el verde del cuadrilátero»

( $c f r$. «caer una lluvia de botes, almohadillas...»).

La relación de solidaridad del adverbio parece preservar la relación del adjetivo base, torrencial, con el sustantivo lluvia (y, si acaso, ?nevada); aunque, en la relación $\mathrm{N}-\mathrm{A}$, parece que el uso de torrencial puede extenderse a otros sustantivos: alud [de nieve], descarga [de objetos], etc.

\section{5) encarnizadamente}

El adverbio encarnizadamente se emplea normalmente con verbos como luchar, pelear, combatir o enfrentarse. Su combinación con verbos como batallar, guerrear, lidiar, etc. parece menos factible porque se pone de manifiesto la redundancia de los rasgos sémicos de encarnizadamente contenidos en las voces batalla, guerra, lid: se trata de la concurrencia de lexemas incompatibles.

También por incompatibilidad, encarnizaủamente difícilmente seleccionará, en su empleo normal, verbos como reñir o discutir, verbos que incluyen en su matriz de rasgos el sema 'enfrentamiento'. Pero, a diferencia de aquellos otros casos, en éstos la incompatibilidad surge por contradicción de rasgos.

Sin embargo, el adjetivo encarnizado suele admitir una nómina más extensa, incluyendo aquellos lexemas que parecían ser incompatibles con el adverbio. Así, 
junto a lucha, pelea, combate, el adjetivo encarnizado puede complementar a batalla, lid, torneo, guerra, y a discusión, disputa, riña, aunque normalmente lo hará en posición antepuesta al núcleo con valor próximo al epíteto: encarnizada batallal? batalla encarnizada, encarnizada discusión/? discusión encarnizada, etc.

6) terminantemente

El adverbio terminantemente parece que sólo puede complementar al verbo prohibir (o a su participio prohibido), tal como reza en numerosos carteles: «Se prohibe terminantemente /Queda terminantemente prohibido arrojar basura». La posición del adverbio en estos casos es bastante limitada: suele presentarse en la misma distribución sintáctica (antepuesto al participio y pospuesto al verbo flexivo).

El adjetivo terminante, en cambio, no conserva con fidelidad la relación de monogamia lingüística que contrae la forma adverbial, ya que, además de su empleo con prohibición, selecciona otros sustantivos: decisión, resultado, propuesta, etc.; esto es, amplía la nómina de lexemas que puede seleccionar su derivado adverbial.

El significado de termiante(mente) es afín al de otras unidades léxicas: categórica(mente), tajante(mente), radical(mente), rotunda(mente); pero éstas no mantienen la relación de solidaridad con la misma rigidez de aquélla.

\section{7) tajantemente}

Aunque la voz tajantemente no la recoge el DRAE, tiene vigencia en contextos en que funciona como modificador de verbos como oponerse, zanjar (un asunto), cortar (una conversación), separar, distinguir, diferenciar, dividir, prohibir, negar, desmentir, etc. (verbos de valoración negativa o que denotan 'oposición' o 'diferenciación'), pero también con afirmar, asegurar, etc. (verbos de valoración positiva). Cabe reparar en que tajantemente no se usa, por ejemplo, con verbos como asentir (*asentir tajantemente), ya que entraña una contradicción: el valor intensificador o ponderativo del adverbio es incompatible con la «acción» atenuada denotada por asentir (frente a afirmar, confirmar, corroborar, asegurar,...).

El adjetivo tajante parece respetar, grosso modo, esta relación de solidaridad en su combinación con sustantivos como oposición, corte, ruptura, negación, rechazo, prohibición,... por un lado, y afirmación, * asentimiento, ... por otro. Además, puede seleccionar sustantivos neutros en la valoración, como postura.

En su función de atributivo o predicativo, se combina también con los verbos ser, manifestarse, mostrarse, pronunciarse, etc. ( «Juan es muy tajante en sus afirmaciones»; "Marcos se mostró tajante cuando tuvo que tomar una decisión»); situación posible para radical-radicalmente, rotundo-rotundamente, categórico-categóricamente. Tajante y sus sinónimos (rotundo, radical, etc.) pueden aparecer como adyacentes de modo o manera en el SP de modo/manera. 


\section{8) categóricamente}

La nómina de unidades léxicas que selecciona categóricamente es posiblemente más reducida. Su empleo normal se limita casi exclusivamente a la presencia de los verbos afirmar (*asentir), ?asegurar y negar, desmentir, oponerse, ?rechazar, ?contradecir,... No parece aceptar otros verbos que, por su significado, podrían concurrir en los mismos contextos, como ?prohibir, ${ }^{*} z a n-$ jar, *cortar, *anular, *impedir, * romper, *distinguir, ?separar, ?dividir, etc.

El adjetivo categórico, en el sentido figurado que se está viendo, tiene un comportamiento similar al de su derivado adverbial, ya que sólo parece seleccionar preferentemente, de acuerdo con los polos de valoración axiológica, los nombres negación (?oposición, ? rechazo) o afirmación; además de los sustantivos declaración, formulación, etc.

Evidentemente, el adjetivo categórico, en su sentido literal ('relativo a las categorías'), complementa a otras clases de sustantivos.

\section{9) radicalmente}

El adverbio radicalmente comparte algunos contextos determinados para tajantemente. Se combina especialmente con los verbos cortar, romper o zanjar, pero también con prohibir, oponerse, ?negar, ?desmentir, ?rechazar,... Por su valor intensificador, se resiste a ser empleado con verbos que implican cierta atenuación, como desestimar (comp. ? «Se desestimó radicalmente la propuesta de los conservadores»).

Sin embargo, radicalmente -frente a tajantemente y categóricamente, que admiten por igual su combinación con verbos de valoración positiva o negativasuele emplearse con menor frecuencia con los verbos de valoración positiva, como afirmar o aceptar (comp. ?«El Ministro de Transportes afirmó radicalmente que se había cuadruplicado el presupuesto para infraestructura de carreteras», ? «Tu hermana aceptó radicalmente mi sugerencia»). Su empleo con verbos que indican atenuación en tal escala de valoración abocaría a una estructura dudosamente gramatical: *asintió radicalmente.

El adjetivo radical, en el sentido indicado, guarda, con respecto al sustantivo, la misma relación que mantiene el adverbio con respecto al verbo: radical:oposición/enfrentamiento/ruptura/separación/rechazo/distinción/ divi-sión/diferenciación/corte/?negación/afirmación,... Ahora bien, radical tiene otras significaciones desconocidas por el adverbio: radical puede aplicarse a personas, movimientos y grupos sociales o políticos, etc. con el significado de 'extremista' o 'conservador'.

\section{0) rotundamente}

También rotundamente parece compartir los mismos contextos que tajantemente o radicalmente: rotundamente se relaciona solidariamente con negar, desmentir, prohibir, rechazar, distinguir, dividir, separar, diferenciar, oponerse, cortar o zanjar (un asunto) y afirmar, asegurar, *asentir, etc. En este 
aspecto, preserva, en general, la relación solidaria existente entre el adjetivo base de que deriva y su núcleo nominal: rotundo :oposición, rechazo, negación, prohibición, ?ruptura, ?separación, ?corte, ?división, *distinción, *discernimiento, *diferenciación,... y afirmación o aseveración, *asentimiento,... La nómina de sustantivos se incrementa con los de valoración neutra declaración o formulación, *postura, etc.

No obstante, al margen de la creatividad propiamente dicha, el adverbio rotundamente llega a emplearse en contextos en los que no aparece expreso ninguno de los verbos indicados: «Todos los partidos políticos han condenado rotundamente la oleada de racismo y xenofobia...» (por el asesinato de un inmigrante dominicano en un pueblo madrileño; TVE, Telediario $1^{\text {a }}$ ed., 29 nov 92).

Sin embargo, el carácter solidario de rotundamente parece más intenso por cuanto que no conoce otros significados que sí posee rotundo; p.e., el significado de 'perfecto', 'total', 'absoluto', cuando rotundo forma grupo sintagmático con nombres como negocio, resultado, triunfo, éxito, fracaso; contextos en que rotundo es sinónimo absoluto de redondo (el DRAE, en la primera acepción de rotundo, lo define como sinónimo de redondo). Ahora bien, rotundo se emplea además con otros sustantivos que no son seleccionados por redondo. Por ejemplo, se habla de lenguaje rotundo, pero no de *lenguaje redondo; inversamente, se habla de números o cuentas redondas, pero no de *cuentas o * números rotundos.

Cabe hacer además otra advertencia. El DRAE recoge la voz redondamente como sinónimo de rotundamente: 'claramente, de modo terminante' (además de la acepción 'en circunferencia, alrededor'), pero no parece que redondamente se emplee con los verbos que selecciona rotundamente: *afirmar redondamente, * prohibir redondamente.

\section{1) herméticamente}

La forma herméticamente selecciona exclusivamente el verbo cerrar $\left({ }^{*}\right.$ tapar, ${ }^{*}$ cubrir, ${ }^{*}$ ocultar, ${ }^{*}$ sellar) o su participio, cerrado, y, en este sentido, preserva la relación de solidaridad que establece el adjetivo hermético con el sustantivo cierre. De hecho, en una de las acepciones de hermético, el DRAE incluye expresamente el sema 'cierre' para la definición de hermético.

No obstante, hermético conoce otros usos figurados que le están vedados a herméticamente. Así, hermético puede aplicarse a voces como mente o mentalidad, filosofía, pensamiento o forma de pensar, poesía, lenguaje, etc. Hermético tiene además un sentido literal, el de 'relativo al filósofo Hermes'.

\section{2) materialmente}

Materialmente sólo selecciona los adjetivos posible e imposible en estructuras oracionales como «ser [algo] —posible/imposible» (atributiva) o «(no) tener/haber - tiempo para...» (predicativa), donde su posición distribucional es bastante rígida. En la última estructura indicada, materialmente conserva la re- 
lación del adjetivo base respecto del sustantivo al que modifica: «(no) tener/ haber tiempo material» (siempre pospuesto). En la estructura atributiva no es posible la presencia de material porque daria lugar a una configuración sintáctica anómala A-A: * «[algo] es material imposible limposible material.

En calidad de adjetivo, material tiene otro significado que le permite combinarse con nombres de objetos que pueden ser, tener o adquirir 'materia'.

\section{3) remotamente}

Alguna razón existirá cuando el DRAE define la voz remotamente con los sinónimos 'lejanamente, apartadamente', ya que dicho adverbio concurre normalmente sólo con las formas lejos (Adv) y lejano o alejado (A), especialmente en la estructura »[algo] queda/está/se halla lejos/alejado de».

Remotamente tiene un valor elativo equivalente al cuantificador mucho (o demasiado) y se usa para indicar la relación entre objetos muy alejados temporal o espacialmente. Por extensión, se emplea en otros tipos de relaciones no físicas: «Esa solución es remotamente practicable» (='difícilmente').

\section{4) mortalmente}

Los verbos herir, golpear, y, si acaso, enfermar (caer enfermo) llegan a entablar una relación de solidaridad con el adverbio mortalmente; relación que mantienen también los respectivos sustantivos deverbales herida, golpe, con el adjetivo base morlal. La relación también se conserva entre mortal y enfermedad, pero no con enfermo (*enfermo mortal), acaso por su originario valor adjetivo.

No obstante, otros significados de mortal hacen posible su combinación con otros nombres: veneno, accidente, etc.; incluso, hombre, ser, etc.

\section{5) perennemente}

El uso de perennemente (perennalmente) queda restringido en la práctica al verbo permanecer y sinónimos (perdurar, durar, conservar(se), ?fijar,...). El adjetivo perenne, en función especificativa, difícilmente se asocia con los sustantivos correlativos a tales verbos: *conservación perenne, *permanencia perenne, *duración perenne,... (comp. perenne permanencia). Sí se aplica, en cambio, a ciertos objetos o seres animados que tienen -0 a los que se les atribuye - la propiedad de 'durar un (largo) período de tiempo': hoja, vida, ?escrito,... («árbol de hoja perenne», «vivir en un sueño perenne», «vivir con una ebriedad perenne», etc.).

\section{6) apoteósicamente}

Aunque el DRAE no registra la voz apoteósicamente, su uso parece posible en expresiones como «aplaudir/celebrar apoteósicamente el éxito», «el equipo ganó apoteósicamente», acaso por un fenómeno de hipálage: «Aplaudir el éxito apoteósico».

El adjetivo apoteósico sí mantiene una clara relación de solidaridad con sustantivos que denotan 'resultado feliz': éxito, resultado, comienzo, término, final, 
debut, inauguración, principio, ?negocio. Las voces principio, debut o inaguración refieren a acciones que son ejecutadas en un período temporal, partes de un evento perfectamente delimitables del resto, por lo que no entran en contradicción con el rasgo 'resultado' («Ha sido un comienzo apoteósico, aunque el final resulte un auténtico fracaso»).

\section{7) perdidamente}

El empleo de perdidamente está limitado al adjetivo participial enamorado, con el que mantiene una relación de solidaridad muy estricta. Su presunto maridaje lingüístico queda esporádicamente quebrantado cuando dicho adverbio selecciona el adjetivo loco: «[alguien] está perdidamente loco».

La forma perdidamente presenta en español un notable contraste con el adjetivo de que deriva. Si bien mantiene la relación de solidaridad del participio perdido con respecto a enamorado y loco (valor superlativo: «(estar) loco perdido/?enamorado perdido), perdido puede seleccionar la nómina de nombres peyorativos cuasisinónimos: idiota, imbécil, tonto, bobo,...; nómina acrecentable con otros signos con valor hiperbólico o superlativo: degenerado, subnormal, mongol, etc. (aunque también con otras voces desposeídas de ese valor, como chulo, petulante, creido, ignorante, etc.). En contraste evidente, perdidamente nunca se combina con ninguno de estos nombres en la citada estructura atributiva: * (estar) perdidamente imbécillidiotal...

Cabe indicar, por un lado, que perdido admite ser o estar cuando se combina con nombres incompatibles con perdidamente (alguien) es tonto/idiota/subnormal perdido - (alguien) está tonto/idiota/subnormal perdido; en cambio, perdido sólo admite estar cuando se combina con enamorado ( y loco): (alguien) está enamorado perdido (o loco perdido), pero *(alguien) es enamorado perdido (o loco perdido). Tal vez este distinto comportamiento se debe a la existencia de cierta incompatibilidad semántica entre ser y enamorado, más que por la resistencia del adjetivo a recibir gradaciones (p.e., tampoco es posible *(alguien) es muy enamorado). Por otro lado, puede señalarse que perdido llega a adquirir un valor adverbial, con carácter fijado de elativo ('mucho'), lo que permite modificar adjetivos (tonto, imbécil). En este sentido, perdido se emparentaria con otros elativos con forma adjetival, como subido: »(alguien) está de un chulo/grosero subido». En la mayoría de los casos, elativos de esta clase suelen combinarse con nombres marcados «negativamente». He aquí un ejemplo más de la estrecha ligazón entre el fenómeno de la solidaridad léxica y el de la fijación lingüística (García-Page 1990a).

\section{8) locamente}

El uso regular de locamente queda limitado al contexto estar _enamorado; locamente y enamorado guardan una relación de solidaridad semejante a la que se establece con perdidamente. 
No obstante, locamente se utiliza con el mismo valor que la loc.adv. a lo loco (a tontas y a locas, a lo tonto) en contextos como hacer lago

$\mathrm{El}$ adjetivo loco no permite hacer ningún tipo de comparación con la forma adverbial, ya que no es posible la concurrencia *loco enamorado [A-A]. Tal secuencia sólo es posible cuando loco es sustantivo; v.gr.: un loco enamorado.

\section{9) rematadamente}

Rematadamente (en sentido figurado, 'totalmente') parece usarse sólo con el adjetivo loco (?tonto) y, en menor medida, con enfermo: estar rematadamente loco/enfermo. No obstante, tal forma adverbial puede emplearse, en su sentido recto, con los adverbios bien, mal: estar rematadamente bien/mal, como lo hará su correspondiente adjetivo, rematado: estar bien/mal rematado; forma que puede aplicarse a una amplia serie de sustantivos (asunto, obra, dibujo, labor, artículo,...; p.e., rematar una obra/una obra muy bien rematada).

Resulta curioso observar que la frase elativa de remate, semánticamente equivalente a rematadamente, pueda aplicarse a una nómina mayor de adjetivos: tonto, loco, idiota, bobo, bolo, *subnormal,... Sin embargo, tal frase no elativiza al adjetivo enfermo, a menos que éste se emplee en lugar de loco: (estar) loco/ tontol *enfermo de remate. Sí son posibles otras frases elativas de intensificación semejante: «Z está loco a base de bien/de narices/de verdad/como una cabra» (García-Page 1990e).

\section{0) literalmente/textualmente}

Para designar la acción de 'reproducir, al pie de la letra' un texto, suelen emplearse casi indistintamente las formas literalmente y textualmente. Aunque pareciera quedar ésta última limitada a los casos de reproducción de textos escritos, lo cierto es que sus ámbitos de aplicación son prácticamente los mismos. Uno y otro se emplean normalmente con los verbos citar, reproducir (un texto), copiar, calcar, (re)transmitir, comunicar, etc., y, por extensión, con los verbos, de significación más general, decir o leer, como en «Su hijo le leyó literalmente la carta», «El letrero dice textualmente...» No obstante, pueden existir algunas diferencias. Así, el uso de verbos como traducir y transcribir resulta normal con literalmente, pero extraño con textualmente: traducir literalmente - ?/*traducir textualmente. No obstante esta restricción más o menos generalizada, tales adverbios conocen de modo esporádico otros contextos inadecuados o no habituales, como muestra el siguiente enunciado: «[con las últimas medidas adoptadas por el Bundersbank] el sistema monetario europeo queda literalmente deshecho» (TVE, telediario $1^{\mathrm{a}}$ ed., 30-7-93).

En algún caso, la elección de uno u otro adverbio se debe al empleo indistinto que pueden recibir. De hecho, el DRAE distingue dos acepciones para literalmente: 'en sentido literal, no figurado o lato' y '(reproducir) al pie de la letra, letra por letra'; y otros dos para textualmente: 'conforme al tex to' y '(reproducir) al pie de la letra'. Tan sólo en la segunda acepción, literalmente y 
textualmente son aparentes sinónimos, por lo que pueden compartir los mismos contextos.

E1 adjetivo literal guarda la misma relación con los sustantivos correspondientes a los verbos señalados: traducción, copia, cita, reproducción, lectura, interpretación,... El adjetivo textual parece restringir la nómina de sustantivos a que se aplica, tal como ocurría con el adverbio: copia, cita, ?reproducción, ?lectura, *traducción, *transcripción.

E1 sustantivo plagio, utilizado para designar la 'copia total y absoluta', difícilmente admite la predicación de literal o textual. Tal situación de incompatibilidad (por redundancia) se observa en la relación entre el verbo plagiar y los adverbios literalmente y textualmente: *plagiar literalmente/textualmente.

21) vertiginosamente

El adverbio vertiginosamente modifica comúnmente a verbos que designan 'ascenso' o, preferentemente, 'descenso' en el espacio o en el tiempo, o en cualquier otra escala gradual. Esta doble aplicación se manifiesta a través del empleo con verbos como caer, descender, decrecer, disminuir, bajar, empeorar, etc. por un lado, y con subir, ascender, crecer, aumentar, incrementar, etc. por otro. Aunque la nómina de verbos que selecciona vertiginosamente es relativamente amplia como para hablar de «solidaridad», lo cierto es que tal adverbio difícilmente aparece en otros contextos que los determinados por los predicados señalados.

El adjetivo vertiginoso también mantiene esta relación con los sustantivos correlativos: subida, descenso, caída, etc.

22) denodadamente

La nómina de predicados verbales que puede seleccionar el adverbio denodadamente es también relativamente amplia, aunque quede limitada, por lo general, a ciertas acciones que implican un esfuerzo (físico o moral) para la consecución de un fin: trabajar, afanarse, luchar, combatir, ?estudiar,...

$\mathrm{El}$ adjetivo correspondiente se resiste a funcionar como predicado de los sustantivos correlativos a tales verbos, a menos que funcione con valor de epíteto en posición antepuesta: un(a) denodado(a) combatel luchal afán/ ?trabajol? estudio. Sin embargo, es frecuente su aplicación a personas que ejercen dicho esfuerzo y, especialmente, a las que lo ejercen con atrevimiento. Es este último rasgo sémico ('atrevimiento', 'valentia') el que parece propiciar la aplicación de tal adjetivo a las personas y a las acciones denotadas por sustantivos en que puede existir riesgo o peligro (y, por tanto, valentía u osadía): combate, etc.; mas no a aquéllas donde no se produce tal situación: ?estudio, ?trabajo.

Es verdad también que el adjetivo denodado, como el adverbio denodadamente, se llega a emplear en ocasiones en las que el rasgo 'osadía' no es pertinente y sí el de 'continuidad', 'afanosidad': «El alumno trabaja/lucha/se afana denodadamente por conseguir el aprobado en junio». 


\section{3) afanosamente}

Igual que denodadamente, afanosamente suele modificar a verbos que designan acciones que requieren 'esfuerzo', pero, a diferencia de aquél, afanosamente no se emplea con verbos que designan acciones que implican 'atrevimiento'. Afanosamente modificará, entonces, a verbos como trabajar, estudiar, luchar (por) -moral o intelectualmente-, pero difícilmente a combatir, pelear, luchar (=guerrear).

El adjetivo correspondiente se aplica a las personas que realizan tales acciones, y, más raramente, a los resultados, esto es, los sustantivos trabajo, estudio, lucha. La compatibilidad de afanoso con tales sustantivos puede deberse al sentido de 'trabajoso, laborioso', 'prolijo', 'detallado' que llega a adquirir ocasionalmente. De hecho, el DRAE recoge la acepción 'muy penoso o trabajoso'.

\section{4) prolijamente}

El adverbio prolijamente se emplea también con verbos cuya acción designada incluye el sema 'esfuerzo', pero siempre y cuando tal rasgo se asocie bien con el de 'pormenorización', 'esmero', bien con el de 'extensión', 'longitud', o con los dos a la vez: trabajar, confeccionar, elaborar, hacer o realizar (algo).

Esa misma exigencia parece gobernar la relación existente entre el adjetivo prolijo y algunos sustantivos correlativos a aquéllos que denotan el resultado de la acción: trabajo, confección, elaboración, estudio.

\section{5) celosamente}

Celosamente ('con celo') se emplea normalmente con verbos como cuidar, vigilar, guardar, ?proteger, ?conservar, ?ocultar, etc. o en expresiones como cumplir un encargoluna obligación.

El adjetivo celoso, en su esporádico empleo como sinónimo de 'cumplidor' o 'puntual'( 1 a acepción del DRAE) no se predica de los sustantivos correspondientes: *celoso: trabajo/ cuidado/ protección..., sino en todo caso de las personas que cuidan o cumplen una misión con celo. Es en este sentido en el que las unidades léxicas celoso y celosamente son semánticamente equivalentes.

No obstante, celoso conoce otro significado que desconoce el adverbio correspondiente, el 'relativo a los celos'. El empleo de celoso con este significado no es sólo el más frecuente, sino prácticamente el único.

\section{6) elocuentemente}

En condiciones normales, sólo los verbc's de lengua, mas no todos, y otros que denotan actividad intelectual admiten ser modificados por el adverbio elocuentemente: hablar, expresarse, exponer (un asunto, un discurso), disertar, comentar, orar, ?teorizar, ?comunicar, ?decir, *convencer, *disuadir,... Generalmente se aplica a exposiciones orales en público de cierto carácter persuasivo y con fines de persuasión. De ahi que verbos como los dos últimos señalados resulten incompatibles (por redundancia). 
El adjetivo elocuente se aplica normalmente, en situaciones idénticas, a las personas que tienen el don de la elocuencia (se dice «persona elocuente»), y, a los hechos o comportamientos que puedan influir en las decisiones: exposición, oratoria, forma de hablar, comentario, ?teoria, ?razonamiento, *convencimiento, *disuasión, etc. (además de nombres como anuncio, dibujo, etc.).

A veces, el rasgo 'para persuadir o convencer' no es pertinente; p.e., en «E1 resultado de las elecciones es bastante elocuente», elocuente tiene un significado próximo a 'revelador, decidor', aunque dicha expresión pueda utilizarse para demostrar (y convencer) al presunto interlocutor la hipótesis sostenida por el emisor. Puede igualmente tratarse de un caso más de impropiedad léxica.

4. Puede decirse, en resumen, que el fenómeno de la solidaridad léxica no parece ser algo privativo de los predicados verbales y adjetivos que seleccionan SSNN (en función de sujeto, objeto, o núcleo nominal), tal como se ha venido señalando tradicionalmente: semejantes relaciones léxico-semánticas se establecen entre ciertas unidades léxicas en -mente y los verbos o adjetivos participiales que modifican (llover: torrencialmente, cerrado: herméticamente). Es difícil, no obstante, que la relación de solidaridad se entable sólo entre dos piezas léxicas: la monogamia lingüística se produce -al igual que con las otras categorías gramaticales - de modo más bien esporádico.

En ocasiones, el adverbio preserva la relación de solidaridad que contrae el adjetivo base de que deriva con el sustantivo correlativo al verbo (lluvia: torrencial, cierre: hermético). Pero los diversos sentidos figurados o no que puede haber adquirido el adjetivo base y que no ha heredado el adverbio sufijado pueden quebrantar este supuesto paralelismo, de forma tal que el adjetivo aparece complementando a otra serie de sustantivos no correlativa a la serie de verbos que modifica la forma en -mente. Lo que es relación de solidaridad para el adverbio puede no serlo para el adjetivo correspondiente (o a la inversa). 


\section{REFERENCIAS BIBLIOGRÁFICAS}

ALARCOS LLORACH, E. (1968), «Verbo transitivo, verbo intransitivo y estructura del predicado», Estudios de gramática funcional del español, 3ํㅡ. ed., Madrid, Gredos, 1980, 148-62.

- (1969), «Aditamento, adverbio y cuestiones conexas», idem, 307-41.

- (1986), «Prólogo» a Martínez (1986).

- (1990a), La noción de suplemento, Logroño, Consej. Educación, Cultura y

Deportes.

- (1990b), «La noción de suplemento», Profesor Francisco Marsá. Jornadas de Filología, Barcelona, Univ. de Barcelona, 209-21.

ÁLVAREZ, M.Á. (1987), “Aditamentos o complementos circunstanciales?», In Memoriam Inmaculada Corrales, Univ. de La Laguna, 1, 47-58.

BEINHAUER, W. (1930), El español coloquial, $3^{\mathrm{a}}$ ed., Madrid, Gredos, 1985.

BLINKENBERG, A. (1960), Le problème de la transitivité en français moderne, Copenhague, Munksgaard.

BOONS, J.P. y OTROS (1976), La structure des phrases simples en français. Constructions intransitives, Ginebra-París, Droz.

BOSQUE, I. (1982), «Más allá de la lexicalización», BRAE, 62:225, 103-58.

- (1983a), «Dos notas sobre el concepto de 'suplemento' en la gramática funcional», Dicenda, 2, 147-56.

- (1983b), «El complemento del adjetivo», LEA, 5:1, 1-14.

- (1989), Las categorías gramaticales. Relaciones y diferencias, Madrid, Síntesis.

CANO, R. (1981), Estructuras sintácticas transitivas en el español actual, Madrid, Gredos.

- (1983), El predicado verbal, Madrid, Coloquio.

COSERIU, E. (1967), «Las solidaridades léxicas», Principios de semántica estructural, Madrid, Gredos, 1977, 143-61.

- (1968), «Las estructuras lexemáticas», idem, 162-84.

CHER VEL, A. (1979), «Rhétorique et grammaire: pétite histoire du circonstanciel», $L F r, 14,5-19$.

DAVID, J. (1976), «Sur quelques approches logiques de la distinction actants/ circonstants», en J. David y R. Martin (eds.), Modèles logiques et niveaux d'analyse linguistique, París, Klincksieck, 193-211.

DIEZ, B. (1987-88), «Sintagmas preposicionales concordados», AO, 37-38, 271-93. EGEA, E.R. (1979), Los adverbios terminados en -MENTE en el español contemporáneo, Bogotá, Instituto Caro y Cuervo.

FERNÁNDEZ, A. (1991), «Sobre la diferenciación entre aditamentos y suplementos y sobre el complemento adverbial», Revista de Filología, 10, 139-58.

GARCfA-PAGE, M. (1990a), «Sobre implicaciones lingüísticas. Solidaridad léxica y expresión fija», Estudios Humanisticos. Filologia, 12, 215-27.

- (1990b), «Léxico y sintaxis locucionales: algunas consideraciones sobre las palabras 'idiomáticas'», Estudios Humanísticos. Filologia, 12, 279-90. 
- (1990c), «Aspectos fónicos en la configuración de los refranes», $N E F, 5,75-121$.

- (1990d), «Propiedades lingüísticas del refrán(I)», Epos, 6, 499-510.

- (1990e), «Frases elativas», Actas del Congreso de la SEL. XX Aniversario, Madrid, Gredos, I, 485-96.

- (1991a), «Locuciones adverbiales con palabras 'idiomáticas'», RSEL, 21:2, 233-64.

- (1991b), «El adverbio en -mente. Motivación contextual en formaciones léxicas anómalas», $A E F, 14,149-81$.

- (1993), «Breves apuntes sobre el adverbio en -mente», Verba, 20 (en prensa). GONZÁLEZ, L. (1991), «Construcciones pronominales y suplemento. (A propósito de las 'construcciones reversibles')", Verba, 18, 411-29.

GUNNARSON, K.A. (1986), «Loin de X, près de X, et parallèlement à X: syntagmes prépositionnels, adjetivaux ou adverbiaux?», FrM, 54, 1-23.

GUTIÉRREZ, M.L. (1986), «El complemento verbal de régimen preposicional en la gramática española», Boletín de la Academia Puertorriqueña de la Lengua Española, 14, 43-60.

- (1987), «Sobre la transitividad preposicional en español», Verba, 14, 367-81. GUTIÉRREZ ORDÓNEZ, S. (1989), «Las solidaridades léxicas», Introducción a la semántica funcional, Madrid, Síntesis, 114-6.

HAAP, H. (1977), «Quelques resultats et problèmes de la recherche valencielle sur le verbe français», Lingvisticae Investigationes, 1:2, 411-34.

- (1978), «Théorie de la valence et enseignement du français», $F r M, 46: 2,97-134$. HERNÁNDEZ, C. (1990), «En torno al suplemento», AdL, 28, 5-25.

HERNANZ, M.L. y BRUCART, J.M. (1987), La sintaxis. Principios teóricos. La oración simple, Barcelona, Crítica.

LEEMAN, D. (1985-86), «À propos du complément circonstanciel», Travaux de Linguistique, 12-13.

LÓPEZ, M.L. (1970), Problemas y métodos en el análisis de las preposiciones, Madrid, Gredos.

MALKIEL, Y. (1959), «Studies in Irreversible Binomials», Lingua, 8, 113-60.

MARTÍNEZ, H. (1986), El suplemento en español, Madrid, Gredos.

MAYORAL, J.A. (1982), «Creatividad léxica y lengua literaria: las formaciones adverbiales en -MENTE», Dicenda, 1, 35-53.

MILLÁN CHIVITE, A. (1988), «Suplemento y dequeísmo: proyección didáctica», Cauce, 11, 137-90.

MOLHO, M. (1980), «Sur la grammaire de l'objet en espagnol», Tralili, 18.

MORAWSKI, J. (1927), «Les formules rimées de la langue espagnole», $R F E, 14,113-33$.

- (1929), «Les formules apophoniques en espagnol et en roman», $R F E, 16,337-65$.

NÁÑEZ, E. (1988), «Sobre el ligamento prepositivo», Homenaje a A. Zamora Vicente, Madrid, Castalia, 1, 459-79.

NICULESCU, A. (1959), «Sur l'objet direct prépositionnel dans les langues romanes», Recueil d'études romanes (Bucarest), 167-85.

PÉREZ, M.R. (1989), «Consideraciones acerca de los complementos adverbiales», Verba, 16, 469-79. 
PORTO, J.Á.(1987a), «Sobre el suplemento: Notas al hilo de una publicación reciente», $B I C C, 42: 1,1-15$.

- (1987b), «Contribución a una teoría de las preposiciones: factores que determinan la elección de éstas en el discurso», BICC, 42:3, 623-46.

- (1992), Complementos argumentales del verbo: directo, indirecto, suplemento y agente, Madrid, Arco/Libros.

- (1993), El complemento adverbial, Madrid, Arco/Libros.

PORZIG, W. (1934), «Wesenhafte Bedeutungsbeziehungen», Beiträge zur Geschichte der deutschen Sprache und Literatur, 58, 70-97.

REBOLLO, M.A. (1976-77), «Algunas observaciones sobre la presencia/ausencia de $a+$ complemento directo», $R L A, 14-15,49-57$.

ROJO, G. (1985), «En torno a los complementos circunstanciales», Lecciones del I y II Curso de Lingüistica Funcional, Oviedo, Univ. de Oviedo, 181-91.

- (1990), «Sobre los complementos adverbiales», Profesor Francisco Marsá. Jornadas de Filología, Barcelona, Univ. de Barcelona, 153-70.

TESNIĖRE, L. (1959), Éléments de Syntaxe Structurale, París, Klincksieck, 1965 (trad. esp. Madrid, Arco/Libros, 1988).

VALLEJO, J. (1925), «Complementos y frases complementarias en español», RFE, $12,117-32$.

VERA LUJÁN, A. (1992), «Sobre la opcionalidad de los complementos adverbiales», Gramma-Temas, 1, 285-314. 